Chapman University

Chapman University Digital Commons

Economics Faculty Articles and Research

Economics

1966

\title{
Bidding Theory and the Treasury Bill Auction: Does Price Discrimination Increase Bill Prices?
}

Vernon L. Smith

Chapman University, vsmith@chapman.edu

Follow this and additional works at: http://digitalcommons.chapman.edu/economics_articles

Part of the American Politics Commons, and the Economics Commons

\section{Recommended Citation}

Smith, Vernon L. "Bidding Theory and the Treasury Bill Auction: Does Price Discrimination Increase Bill Prices?" Review of Economics and Statistics, 48.2 (1966): 141-146

This Article is brought to you for free and open access by the Economics at Chapman University Digital Commons. It has been accepted for inclusion in Economics Faculty Articles and Research by an authorized administrator of Chapman University Digital Commons. For more information, please contactlaughtin@chapman.edu. 


\section{Bidding Theory and the Treasury Bill Auction: Does Price Discrimination Increase Bill Prices?}

\section{Comments}

This article was originally published in Review of Economics and Statistics, volume 48, issue 2, in 1966.

\section{Copyright}

MIT Press 


\title{
BIDDING THEORY AND THE TREASURY BILL AUCTION: DOES PRICE DISCRIMINATION INCREASE BILL PRICES? *
}

\author{
Vernon L. Smith
}

\section{Introduction and Summary}

$\mathbf{R}$ ECENT DISCUSSIONS by Milton Friedman [4] and Deane Carson [2] have independently suggested that the Treasury should abandon the policy of price discrimination in the weekly auction of 91-day and 182-day Treasury bills. They would substitute a simulated purely competitive auction in which all bids are filled at a uniform market-clearing price determined by the intersection of the offer quantity and the demand array of submitted bids. Andrew Brimmer [1, p. 181] challenged this view, arguing in favor of price discrimination on the ground that efficient ". . . resource allocation should be subordinated to the minimization of interest cost to the Treasury. ..." This conclusion requires the assumption, stated explicitly by Brimmer [1, p. 178] that, "Through auctioning new bills (at discriminatory prices), the United States Treasury receives higher prices than it could get by selling these issues at a single price."

This paper is not directed to the question of whether the Treasury should or should not practice in the public sector what the Clayton Act prohibits in the private sector. The paper is concerned exclusively with the theoretical question of whether the Treasury would necessarily receive higher prices by employing price discrimination than it could get by selling the issues at a single price. From a theory of bidding under uncertainty, which seems to apply naturally to the Treasury auction, it will be shown that buyers may be expected to enter lower bids under price discrimination than they would for a simulated competitive auction. If this analysis is accepted, it suggests that the Treasury may actually get less revenue from a given bill offering under price discrimination than under a competitive auction.

Various approaches might be used in attempting to build a model of bidding behavior

* This paper was prepared while the author was a member of the Ford Foundation Faculty Research Seminar on Experimental Economics, Carnegie Institute of Technology, August 1964. in the bill auction. My approach will assume that bidders desire to maximize expected utility, where the expectation is over a subjective probability density function for the lowest accepted bid. That is, whether we are designing a discriminatory auction model or a purely competitive auction, each bidder is assumed to associate a subjective probability with each possible value for the minimum successful bid. Within this framework, three models will be discussed. Model I assumes each bidder has a fixed specified limit price at which he is willing to buy a specified quantity of bills. I intend this model to serve as an abstract representation of the behavior of non-dealer participants in the bill auction - banks, corporations and insurance companies - who act more or less as final holders of the bills. It is assumed in Model II that each bidder attaches a subjective probability density to the price at which he can resell new bills bought at auction from the Treasury. I think of this model as applying to the government security dealers who participate in the auction. Such dealers face not only the uncertainty, experienced by all bidders, as to where the low bid will fall, but also uncertainty as to the price that can be obtained by retailing the new bills in the secondary market for outstanding bills. In both Models I and II, the decision variable is the bid price. Model III is a generalization of II in which the decision variables are the bid price and the quantity of bills to be specified in the bid. From Models I and II, it is possible to show, unambiguously, that an individual will make at least as low a bid (and most probably lower) in a discriminatory auction as in a single-price competitive auction. From Model III, which seems to be less tractable, the case rests with an example in which an individual's bid price is less, and the quantity of bills specified in the bid is less, under discrimination.

\section{Mechanics of the Bill Auction}

The weekly bill auction begins each Wednes- 
day when the Treasury releases an announcement, through the reserve banks, inviting tenders for specified amounts of 91-day and 182-day issues. The weekly offering of 91-day issues amounts to around $\$ 1$ billion, that of the longer issue about half a billion dollars. The resulting bids are normally tendered the following Monday to each Reserve Bank by the bill investors in each Federal Reserve district. Delivery is made to the successful bidders on the following Thursday. Before 1947, all bids had to be entered at a specified price. Since 1947 , small investors have been accommodated by permitting the option of submitting noncompetitive bids for limited amounts of bills ( $\$ 100,000$ or less for 182 -day bills, $\$ 200,000$ or less for 91-day bills). The successful competitive bids are filled at their individual bid prices, while the non-competitive bids are filled at a quantity weighted average of the accepted competitive bids. These "noncompetitive" bids perform, for the price discriminatory auction, a role analogous to the order "buy at market or better" used in the organized stock exchange auctions. That is, each of these institutional forms of bidding permits the buyer to be certain of making a purchase, though at the cost of having to risk the payment of a higher price. Since the noncompetitive bids do not enter directly into the determination of bill auction prices, this type of bid will not be analyzed in what follows. Clearly, if all bids were noncompetitive, auction prices would be indeterminate.

To illustrate price determination, suppose that the net offering of 91-day bills to the competitive bidders is $Q_{o}$ in figure 1 . $Q_{o}$ would be the total offering minus the amount of noncompetitive bids. (This arithmetic makes clear how the noncompetitive bids exert an indirect influence on price determination.) The array of competitive bids from highest to lowest forms an effective demand, $d d$, for the offering. The lowest accepted bid would be at $P_{L}$ the highest at $P_{H}$.

In this illustration, the gross receipts from the offering are given by the area below $d d$ and $S S$ in figure 1 . With respect to the effective demand curve, $d d$, the seller acts as a "perfect" price discriminator. By contrast, if this market were operated to simulate a purely competitive auction, and if we assume the same bids to have
FIGURE 1

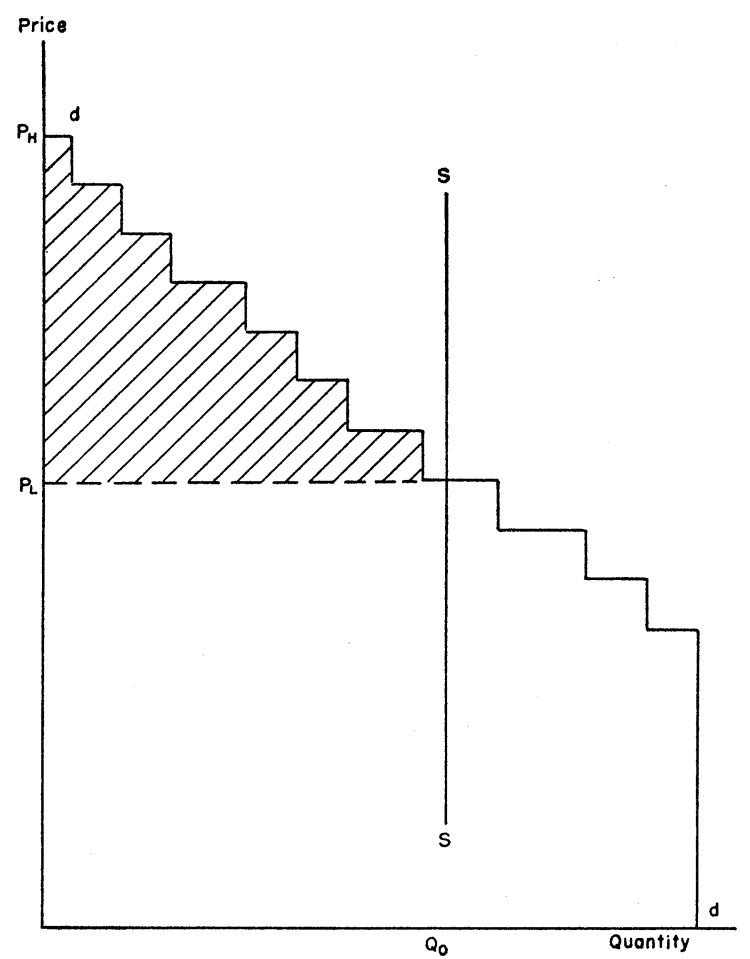

been submitted as in the example for price discrimination, the result would have been the uniform market-clearing price, $P_{L}$, for all successful bidders. Under these assumptions, and this seems to be the accepted reasoning, the Treasury receives greater revenue from the offering as a consequence of practicing price discrimination. However, as will be demonstrated in later sections, it is not reasonable to suppose the bids will be the same under the two forms of auctions [3, pp. 391-392].

To illustrate, suppose each bidder, $i$, in the market, has a firm reservation price, $P_{i}$, that he is willing to pay for a unit or lot of the bills traded. Then the "potential" demand, or limit price set, is determined by the ordered set $\left\{P_{i}\right\}$ arrayed in descending order from highest to lowest. Such a set is illustrated by $D D$ in figure 2 , and corresponds to the demand curve of ordinary price theory. From the analysis below, however, when a buyer knows that a successful bid will be filled at his bid price, he will tend to bid lower than if he knows it will be filled at the marginal bid price of all buyers. If the limit price set is $D D$, which is the demand under a simulated competitive auction, then the ef- 
FIgURE 2

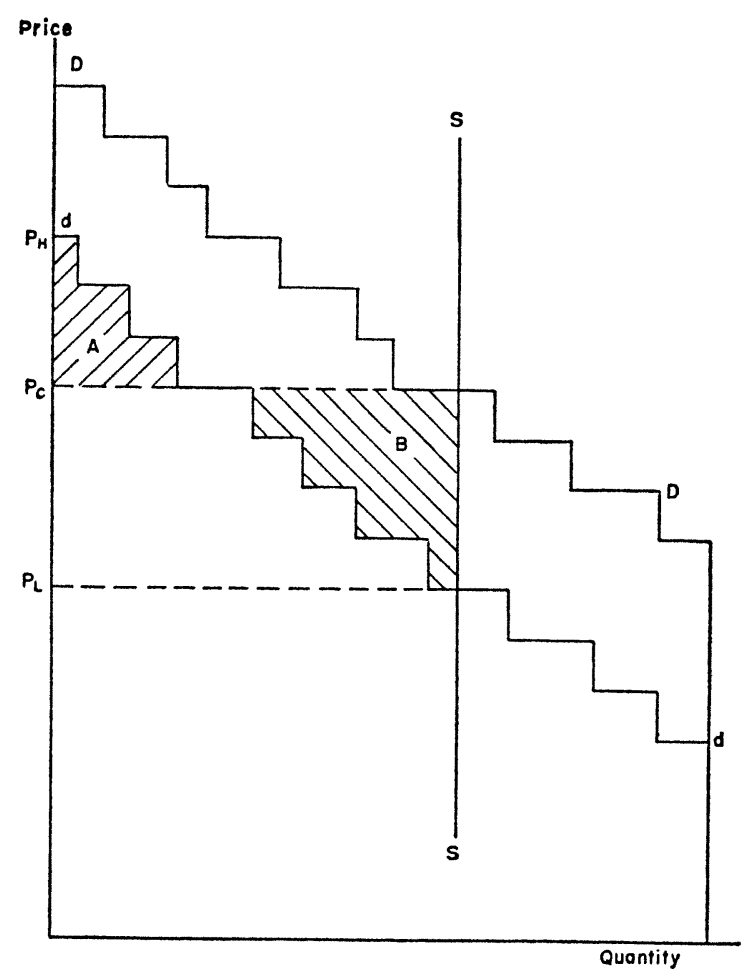

fective demand, $d d$, under price discrimination might be as shown in figure 2 . It follows that for a given $D D$, and a single auction, price discrimination might yield the Treasury more or less revenue than the proposed competitive auction. A seller gets less revenue under price discrimination if area $A<$ area $B$ in figure 2 . Over time, with repeated bidding in successive weekly Treasury auctions, if $D D$ and $S S$ conditions were constant, it is clear that the unsuccessful bidders in earlier auctions would tend to raise their bids, while the successful bidders would tend to lower their bids. Consequently, area $B$ would approach zero, as the lower part of $d d$ rose toward $D D$. In the bill auction, however, both $D D$ and $S S$ change from one auction to another. Indeed, the change is sometimes so great that the range of accepted bids for one week does not overlap the range for the following week [4]. Hence, the price uncertainties which lead one to expect $d d$ to be below $D D$ may persist indefinitely over time.

\section{Model I: A Theory of Non-Dealer Bidding Behavior}

This section presents an elementary static expected utility maximization model of nondealer bidding behavior in the two alternative kinds of auction markets. Based upon the resource and opportunity situations faced by such a bidder, it is assumed that the individual has a fixed limit price above which he will not bid for a unit or lot of Treasury bills, in a specific auction. If $P$ is the given limit price and $p$ is his bid price to be determined, the individual's choices are assumed to be governed by a utility function for money, or "rent," $U(P-p)$, if his bid is accepted, 0 , if it is rejected. Since the purchase lot size is fixed in this model it can be set equal to unity without loss of generality. Finally, we suppose that the individual would have a subjective density function, $f(x)$, for the minimum successful bid, $x$, if he were bidding in a discrimination auction, and $g(x)$, if he were bidding in the proposed single-price competitive auction.

With these assumptions, in a discrimination auction a von-Neumann-Morgenstern expected utility maximizer should choose his bid, $p$, so as to maximize:

$$
E_{D}(U)=\int_{0}^{p} U(P-p) f(x) d x, 0 \leq x \leq P .
$$

A maximum occurs at $p^{0}$ on this interval if:

$$
\begin{aligned}
& \frac{\partial E_{D}}{\partial_{p}}=U\left(P-p^{0}\right) f\left(p^{0}\right)-U^{\prime}\left(P-p^{0}\right) F\left(p^{0}\right) \\
& \left\{\begin{array}{l}
>0, p^{0}=P \\
=0, p^{0}=p^{*} \text { (interior solution) }
\end{array}\right.
\end{aligned}
$$

For an interior maximum at $p^{*}$, one must also have

$$
\begin{aligned}
\frac{\partial^{2} E_{D}}{\partial p^{2}} & =U\left(P-p^{*}\right) f^{\prime}\left(p^{*}\right)-2 U^{\prime}\left(P-p^{*}\right) f\left(p^{*}\right) \\
& +U^{\prime \prime}\left(P-p^{*}\right) F\left(p^{*}\right)<0 .
\end{aligned}
$$

The inequality in (2) can be taken as a postulate, or if we assume diminishing marginal utility, $U^{\prime \prime}<0$, and a unimodal density, $f(p)$, then the inequality necessarily holds for solutions $p^{*}$ above the mode, since in that region $f^{\prime}(p)<0$. Figure 3 illustrates an interior solution at $D$ (discrimination).

In a competitive auction, by contrast, since all bids are filled at the uniform market clearing price, $x$, expected utility to an individual entering a single bid is:

$$
E_{\sigma}(U)=\int_{0}^{p} U(P-x) g(x) d x, 0 \leq p \leq P .
$$


FIgURE 3

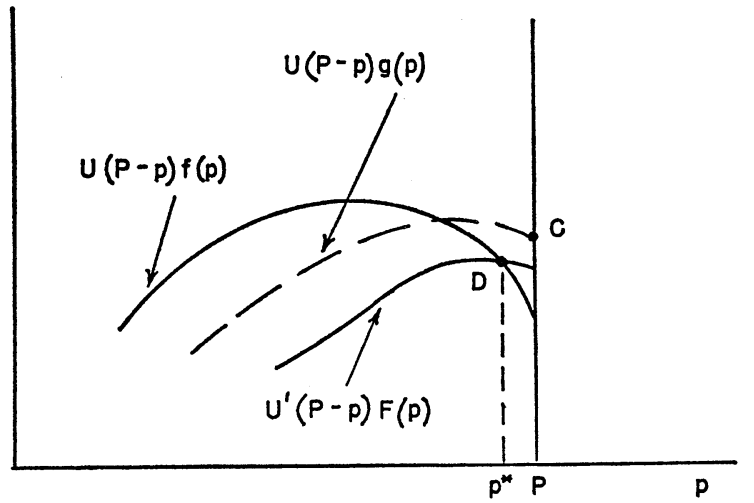

For a maximum of $E_{C}(U)$ at $p^{0}$,

$$
\frac{\partial E_{C}}{\partial_{p}}=U\left(P-p^{0}\right) g\left(p^{0}\right)\left\{\begin{array}{l}
>0, p^{0}=P \\
=0, p^{0}=p^{* *}
\end{array} .\right.
$$

But, if $U(P-p)>0$, and $g(p)>0$ on $0 \leqslant p$ $\leq P$, the equality condition can never be satisfied. Therefore, as is intuitively obvious, in competitive auctions the expected utility maximizer will bid his full limit price, $P$. There is no penalty for winning the bid at a quotation above the market clearing price so the bidding problem reduces to one of maximizing the chance of success. This is accomplished by bidding the maximum price $P$, as illustrated in figure 3 at point $C$ (competition).

The conclusion is that a non-dealer would never bid higher under discrimination than under competition, and given the variety of $U$ 's and $f(x)$ 's likely to be encountered in real bidders, we should expect a tendency toward solutions $p^{0}=p^{*}<P$ under discrimination.

The model can be extended to include the case where an individual desires to enter bids for several lots of bills, and has limit prices $P_{1}<P_{2}<P_{3}<\ldots$, for each lot.

\section{Model II: A Theory of Dealer Bidding Behavior}

The distinguishing feature of dealer operations in the bill auction is that they acquire new bills for resale in the secondary market. Their livelihood depends upon an ability to resell such bills, on the average, at more favorable terms than they acquire them. Their profits are squeezed from below by uncertainty as to how high the range of accepted bids will be, and from above by uncertainty as to how low the price at which they turn the bills in the secondary market will be.

For a given lot of bills, we again assume a utility function $U(P-p)$ if the bid at price $p$ is accepted, 0 , otherwise, with subjective densities $f(x)$ and $g(x)$, respectively, for the lowest accepted bid in the discriminatory and competitive auctions. In addition, for the dealers, we assume a subjective probability density $h(P)$ for the price $P$ at which the bills may be peddled in the secondary market. The density $h(P)$ is assumed to be the same regardless of the type of auction.

In the discriminatory auction expected utility is now:

$$
E_{D}(U)=\int_{0}^{\infty} \int_{0}^{p} U(P-p) f(x) h(P) d x d P .
$$

Expected utility is maximum at $p^{*}$ if:

$$
\frac{\partial E_{D}}{\partial \hat{p}}=f\left(p^{*}\right) I\left(p^{*}\right)+F\left(p^{*}\right) I^{\prime}\left(p^{*}\right)=0
$$

which can be written

$$
I\left(p^{*}\right)=-\frac{\mathrm{F}\left(p^{*}\right)}{f\left(p^{*}\right)} I^{\prime}\left(p^{*}\right),
$$

and if:

$$
\begin{aligned}
\frac{\partial^{2} E_{D}}{\partial \hat{p}^{2}} & =2 f\left(p^{*}\right) I^{\prime}\left(p^{*}\right)+I\left(p^{*}\right) f^{\prime}\left(p^{*}\right) \\
& +F\left(p^{*}\right) I^{\prime \prime}\left(p^{*}\right)<0,
\end{aligned}
$$

where

$$
\begin{aligned}
I\left(p^{*}\right) & =\int_{0}^{\infty} U\left(P-p^{*}\right) h(P) d P, I^{\prime}\left(p^{*}\right) \\
& =-\int_{0}^{\infty} U^{\prime}\left(P-p^{*}\right) h(P) d P .
\end{aligned}
$$

By substituting for $I\left(p^{*}\right)$ from (4), this last condition can be written:

$$
\begin{aligned}
\frac{\partial^{2} E_{D}}{\partial \hat{p}^{2}} & =I^{\prime}\left(p^{*}\right)\left[2 f\left(p^{*}\right)-\frac{F\left(p^{*}\right) f^{\prime}\left(p^{*}\right)}{f\left(p^{*}\right)}\right] \\
& +F\left(p^{*}\right) I^{\prime \prime}\left(p^{*}\right)<0 .
\end{aligned}
$$

In a competitive auction, expected utility for the same dealer would be:

$$
E_{C}(U)=\int_{0}^{\infty} \int_{0}^{D} U(P-x) g(x) h(P) d x d P .
$$

A maximum at $p^{* *}$ requires

$$
\frac{\partial E_{C}}{\partial p}=g\left(p^{* *}\right) I\left(p^{* *}\right)=0 \text {, or }
$$




$$
\begin{aligned}
& I\left(p^{* *}\right)=0, \text { if } g\left(p^{* *}\right)>0, \\
& \frac{\partial^{2} E_{C}}{\partial_{p}^{2}}=g\left(p^{* *}\right) I^{\prime}\left(p^{* *}\right)<0, \text { or } \\
& I^{\prime}\left(p^{* *}\right)<0, \text { if } g\left(p^{* *}\right)>0 .
\end{aligned}
$$

Now, in figure 4 illustrating the solutions (4)

FIGURE 4

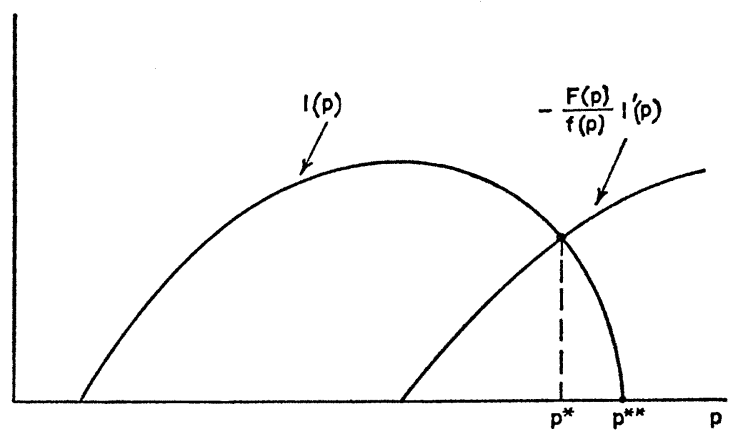

and (6) it is seen that $p^{*}<p^{* *}$, since, from (7), $I^{\prime}(p)<0$ and therefore $-\frac{F(p)}{f(p)} I^{\prime}(p)>0$ in the neighborhood of $p^{* *}$.

The conclusion is that a dealer submitting a single bid may bid lower in a discrimination auction than in the proposed competitive auction.

\section{Model III: A Generalization of II}

The previous models assume that the quantity of bills to be taken by the individual bidder is fixed, with only the bid price a decision variable. Consider now the dealer case where both the price, $p$, and the quantity, $Q$, specified in the sealed bid are decision variables. It is assumed that the dealer will retail the entire quantity of bills at a price $P$, given by a subjective probability density function $h(P)$.

Proceeding as before, expected utility under the discriminatory organization of the market is:

$$
E_{D}(U)=\int_{0}^{\infty} \int_{0}^{p} U[(P-p) Q] f(x) h(P) d x d P .
$$

Necessary conditions for a maximum of $E_{D}(U)$ at $\left(p^{*}, Q^{*}\right)$ are:

$$
\begin{aligned}
& \frac{\partial E_{D}}{\partial p}=f\left(p^{*}\right) \int_{0}^{\infty} U\left[\left(P-p^{*}\right) Q^{*}\right] h(P) d P \\
& -F\left(p^{*}\right) \int_{0}^{\infty} Q^{*} U^{\prime}\left[\left(P-p^{*}\right) Q^{*}\right] h(P) d P=0
\end{aligned}
$$

$$
\begin{aligned}
\frac{\partial E_{D}}{\partial \boldsymbol{Q}}= & F\left(p^{*}\right) \int_{0}^{\infty}\left(P-p^{*}\right) U^{\prime} \\
& {\left[\left(P-p^{*}\right) Q^{*}\right] h(P) d P=0 . }
\end{aligned}
$$

Now suppose utility is quadratic in money. It is well-known that if the expected utility axioms are satisfied, then any positive linear transformation of a utility function is also a utility function. Therefore, we do not lose any generality by working with a one-parameter quadratic utility $U(m)=m-a m^{2}$, where $m$ is money. For this case (8) and (9) can be put in the form:

$$
\begin{aligned}
& Q^{*}=\frac{\left(\bar{P}-p^{*}\right)-\frac{F\left(p^{*}\right)}{f\left(p^{*}\right)}}{a\left[V(P)+\left(\bar{P}-p^{*}\right)^{2}-2\left(\bar{P}-p^{*}\right) \frac{F\left(p^{*}\right)}{f\left(p^{*}\right)}\right]} \\
& Q^{*}=\frac{\bar{P}-p^{*}}{2 a\left[V(P)+\left(P-p^{*}\right)^{2}\right]}
\end{aligned}
$$

where $\bar{P}$ and $V(\bar{P})$ are the mean variance of the density $h(P)$, and $F\left(p^{*}\right)=\int_{0}^{p^{*}} f(x) d x$. By eliminating $Q^{*}$ between (10) and (11) we get the following implicit function in $p^{*}$ :

$$
\begin{gathered}
\left(\bar{P}-p^{*}\right) V(P)+\left(\bar{P}-p^{*}\right)^{3} \\
-2 \frac{F\left(p^{*}\right)}{f\left(p^{*}\right)} V(P)=0
\end{gathered}
$$

with $Q^{*}$ given by either $(10)$ or $(11)$, once $p^{*}$ is determined from (12).

In the numerical example below we consider the special case of (11) and (12) where the density $f(p)=\frac{1}{3} e^{-3(\hat{P}-p)}$ a member of the gamma family. Then $F(p)=\frac{1}{9} e^{-3(\hat{P}-p)}$, and $\frac{F(p)}{f(p)}=\frac{1}{3}$. Hence, (12) can be written as a cubic, which, if we make the substitution $y=\bar{P}-p^{*}$ will be:

$$
3 y^{3}+3 V(P) y-2 V(P)=0 .
$$

In the competitive auction, expected utility would be:

$$
E_{C}(U)=\int_{0}^{\infty} \int_{\substack{0 \\ g(x) h(P) d x d P}}^{p} U[(P-x) Q]
$$


with necessary conditions for a maximum at $\left(p^{* *}, Q^{* *}\right)$ given by:

$$
\begin{aligned}
& \frac{\partial E_{\sigma}}{\partial p}=g\left(p^{* *}\right) \int_{0}^{\infty} U\left[\left(P-p^{* *}\right) Q^{* *}\right] h(P) d P=0, \\
& \frac{\partial E_{C}}{\partial \hat{Q}}=\int_{0}^{\infty} \int_{0}^{p^{* *}}(P-x) U^{\prime} \\
& {\left[(P-x) Q^{* *}\right] g(x) h(P) d x d P=0 . }
\end{aligned}
$$

As above, let $U(m)=m-a m^{2}$. Then (13) and (14) can be written:

$$
\begin{aligned}
& Q^{* *}=\frac{\bar{P}-p^{* *}}{a\left[V(P)+\left(\bar{P}-p^{* *}\right)^{2}\right]}, \\
& Q^{* *}=\frac{\int_{0}^{p^{* *}}(\bar{P}-x) g(x) d x}{2 a \int_{0}^{p^{* *}}\left[V(P)+(\bar{P}-x)^{2}\right]} g(x) d x .
\end{aligned}
$$

Where $g(x)$ is the gamma density $\frac{1}{2} e-2(\hat{P}$ $-x)$, then in (16) we have

$$
\begin{aligned}
\int_{-\infty}^{p^{* *}}(\bar{P}-x) e^{-2(\hat{P}-x) d x} & =1 / 4(\bar{P}-p+1 / 2) e^{-2(\hat{P}-p)},
\end{aligned}
$$

and

$$
\begin{aligned}
\int_{-\infty}^{p^{* *}}[V(P) & \left.+(\bar{P}-x)^{2}\right] e^{-2(\hat{P}-x) d x} \\
& =1 / 2\left\{1 / 4\left[V(P)+\bar{P}^{2}\right]-\bar{P}(p\right. \\
& -1 / 2)+1 / 2\left(p^{2}-p\right. \\
& +1 / 2)\} e^{-2(\hat{P}-p)} .
\end{aligned}
$$

Then from (15) and (16), making the substitution $z=\bar{P}-p^{* *}$, gives the cubic

$$
2 z^{3}+3 z^{2}+[1+V(P)] z-V(P)=0 \text {. }
$$

Now consider the following numerical counter example to the hypothesis that the Treasury receives higher prices under price discrimination, than if the bills were sold at purely competitive auction. Let the subjective density $h(P)=e-(\hat{P}-p)$; also gamma. We note that $h(P), g(x)$, and $f(p)$, have means $\hat{P}-1$, $\hat{P}-2, \hat{P}-3$, and variances $V(P)=1, V(x)$ $=4$, and $V(p)=9$. These parameters are consistent with a presumption that traders would expect the lowest accepted bid $p$ in a discrim- inatory auction to be below the lowest accepted bid $x$ in a competitive auction, which in turn is expected to be below the price $P$ at which the bills can be resold in the secondary market. Also note that in all three density functions $\hat{P}$ is an upper bound on subjective bill prices. We assume $\hat{P}=100$, i.e., no trader believes it possible that bill prices can exceed 100 either purchased at auction or at resale. No doubt it is unrealistic to suppose that the most likely price is $\hat{P}=100$ in each case, but we make this compromise with realism in the interests of computational simplification. Our purpose is to provide a counterexample, and if there is one there are surely millions!

From the numerical values $\hat{P}=100, V(P)$ $=1, \bar{P}=\hat{P}-1=99$, the cubic (12a) becomes $3 y^{3}+3 y-2=0$ with the real positive root $y^{*} \cong 0.52$. Hence $p^{*}=P-y^{*} \cong 98.48$. If we assume $a=10^{-4}$, then substituting the appropriate numbers into (11) gives $Q^{*} \cong 2000$. Substituting the numbers into (17), gives the cubic:

$$
2 z^{3}+3 z^{2}+2 z-1=0,
$$

with real positive root $z^{* *} \cong 0.32$. Hence $p^{* *}=\bar{P}-z^{* *} \cong 98.68$, and from (15) $Q^{* *}$ $\cong 2900$.

Consequently, in this example, the dealer in a competitive auction bids 98.68 , and desires to purchase 2,900 bills at that bid. In a discriminatory auction he would not only bid less (98.48) but also take fewer bills $(2,000)$.

\section{REFERENCES}

[1] Andrew Brimmer, "Price Determination in the United States Treasury Bill Market," This Review, XLIV (May 1962).

[2] Deane Carson, "Treasury Open Market Operations," This Review, XLI (Nov. 1959).

[3] Henry Goldstein, "The Friedman Proposal for Auctioning Treasury Bills," Journal of Political Economy, 70, No. 4 (Aug. 1962), 386-392.

[4] U.S. Congress, Joint Economic Committee, Hearings: Employment, Growth, and Price Levels, Part 9A, "Constructive Suggestions for Reconciling and Simultaneously Obtaining the Three Objectives of Maximum Employment, and Adequate Rate of Growth, and Substantial Stability of the Price Level, 86 th Congress, First Session (Oct. 1959), 3023-3026. Also see Milton Friedman, A Program for Monetary Stability (New York, 1960), 63-65. 